\title{
PENINGKATAN KEMAMPUAN KARYAWAN MELALUI PENGEMASAN DAN MANAJEMEN KEUANGAN PADA INDUSTRI KERIPIK BUAH-BUAHAN
}

\author{
A. Zainul Arifin ${ }^{1)}$, Sulistyawati' ${ }^{2)}$, Deny Utomo ${ }^{3)}$ \\ ${ }^{1)}$ Fakultas Pertanian, Universitas Merdeka Pasuruan \\ email : ahmad23unmer@gmail.com \\ ${ }^{2)}$ Fakultas Pertanian, Universitas Merdeka Pasuruan \\ email : mommyandri@gmail.com \\ ${ }^{3)}$ Fakultas Pertanian, Universitas Yudharta Pasuruan \\ email : denyut369@gmail.com
}

\begin{abstract}
Olivia Jaya and Afalia Jaya is an industry that moves on the chips fruits. The lack of knowledge about the packaging and good financial management in industrial chips fruits cause the product unattractive and archive financial management is not arranged. Training on packaging and financial maanjemen is appropriate for the conditions in the industry Olivia Jaya and Afalia Jaya. Packaging is focused on appropriate ways and correct packaging, so that the resulting product is attractive and the quality remains. Financial management training focused on the use of computers for financial management applications, so that the financial records will be neatly arranged. The method used is lectures and application use financial management software. Achievement on the packaging training and financial management in industrial chips fruits are mostly participants partners to implement packaging properly and can implement financial management through a computer.
\end{abstract}

Keywords: packaging, financial management, fruit chips

\section{PENDAHULUAN}

Desa Kambingan termasuk salah satu desa yang masuk Kecamatan Tumpang, Hasil pertanian dari desa ini berupa jagung, singkong, ubi jalar, tomat, sawi, bayam, kangkung, dan tanaman padi. Hasil buah-buahan yang terdapat di desa ini, antara lain; rambutan, salak, nangka, pepaya, pisang, dan alpukat. Lokasi desa ini terletak jauh dari kota Malang sekitar $40 \mathrm{Km}$. Transportasi angkutan ke pedesaan ini masih jarang sekali. Keadaan ini menyebabkan masyarakat desa Kambingan masih belum optimal dalam mengakes informasi, khusuSnya informasi teknologi yang terbaru.

Desa Kambingan merupakan desa yang memiliki beberapa unit usaha kecil yang mengolah buah-buahan menjadi makanan ringan berupa keripik buah. Kelompok usaha kecil yang saat ini masih berproduksi secara terus-menerus dalam pengolahan keripik buah-buahan adalah kelompok usaha kecil Usaha Dagang (UD) Olivia Jaya milik bapak Muslimin dan UD. Afalia Jaya milik bapak Dukan. Dua kelompok usaha ini adalah unit usaha kecil berskala industri rumah tangga dan tentunya banyak permasalahan yang belum terselesaikan.

Kualitas rasa produk keripik buah-buahan dari kedua unit usaha kecil ini sangat digemari oleh masyarakat di desa Kambingan dan di luar wilayah desa Kambingan. Permintaan yang semakin meningkat dari para pedagang baru yang ingin bekerjasama dengan kedua UD. ini membuat bapak Muslimin dan bapak Dukan kewalahan dalam memproduksi keripik buah-buahan. Namun ada beberapa kendala yang dialami oleh kedua unit usaha ini, yang pertama adalah kendala dari segi pengemasan yang dilakukan oleh kedua UD ini masih menggunakan sealer biasa dalam artian untuk penggembungan gas pada kemasan masih dilakukan dengan cara meniup pada kemasan oleh para pekerja maupun pemilik, kemudian setelah dilakukan peniupan kemasan langsung ditutup dengan sealer. Kendala kedua adalah dari sistem manajemen, baik pengelolaan SDM, keuangan maupun pemasaran. Sistem administrasi pada manajemen keuangan masih belum tertata rapi dan hanya berdasarkan ingatan saja. Hal ini terjadi karena para pemilik tidak pernah mengetahui bagaimana cara mengelola perusahaan dengan baik dari aspek manajemen dan ini diperparah dengan tidak adanya komputer yang berfungsi sebagai manajemen arsip untuk pengelolaan keuangan maupun pengarsipan yang lainnya. Keterbatasan 
informasi dan tingkat pendidikan yang rendah dari seluruh tenaga kerja di kedua UD ini menyebabkan usaha ini kurang berkembang secara pesat. Tingkat pendidikan tenaga kerja yang rata-rata masih SD menyebabkan kurangnya pengetahuan tentang adopsi teknologi dan pengelolaan keuangan.

Pengemasan mencakup keseluruhan konsep termasuk kemasan langsung, bagian luar, pembungkus dan lain-lainnya, dan bagian yang keseluruhannya berperan dalam pemasaran dan pemajangan (Setiawan et al., 2013). Sebuah kemasan yang buruk bisa memberikan citra yang jelek terhadap suatu produk yang sangat baik (Danger, 1992 dalam Natadjaja et al., 2009). Pengemasan yang baik juga harus melakukan pelabelan pada produk, salah satu informasi dari pelabelan tersebut adalah tanggal kadaluarsa (Sulaawaalia, 2009).

\section{METODE PENELITIAN}

\section{Rancangan kegiatan}

Lingkup kegiatan ini dilaksanakan mulai dari bulan Januari hingga Juli 2015, yaitu bermula dari persiapan dalam tim pelaksana, mempersiapkan lokasi dan mitra kerja, pelaksanaan praktek dan peninjauan keberlanjutan kegiatan.

\section{Khalayak Sasaran}

Pemilihan mitra kerja dilihat dari keseriusan, keaktifan dan keberlanjutan organisasi yang terdapat di Desa kambingan. Penentuan mitra kerja ini dianggap sangat penting karena menjadi salah satu indikator keberhasilan kegiatan. Organisasi yang disurvei kondisi dan keberadaannya meliputi Ud. Olivia Jaya dan UD. Afalia Jaya. Hasil survei yang meliputi wawancara dan observasi mengarah pada kedua mitra sebagai mitra kerja yang sesuai.

Kondisi ini diperkuat karena organisasi ini dianggap aktif, organisasi yang terarah serta didukung oleh interaksi yang baik anatar karyawan. Hal ini diharapkan agar keberlanjutannya adalah dapat mentransfer ketrampilan yang didapatkan saat kegiatan pada karyawan yang lain.

\section{Alat}

Alat yang digunakan adalah satu buah unit computer lengkap dan software unutk manajemen keuangan

\section{Desain dan kinerja alat}

Peralatan yang digunakan pada kegiatan ini sederhana dan lebih praktis yang dirancang sesuai dengan kondisi pedesaan, yaitu hemat energi, mudah digunakan, efesien dalam produktivitas, mudah dipindah-pindahkan dan mudah dalam perawatannya. Pada kegiatan ini menggunakan peralatan computer dan software manajemen keuangan.

\section{Teknik pengumpulan data dan analisis data}

Kegiatan ini lebih diarahkan pada target luaran, yaitu mitra kerja trampil dalam menggunakan peralatan untuk melakukan manajemen keuangan dan desain kemasan. Pengumpulan data dilakukan dengan melakukan wawancara pada pengurus UD. Olivia Jaya dan Afalia Jaya. Pengumpulan data ini dimaksudkan untuk mengetahui status sosial, pendidikan dan motivasi mitra kerja dalam kegiatan IbM yang dilaksanakan agar target luaran dapat tercapai.

Target luaran dinilai pada saat pelaksanaan kegiatan praktek penggunaan software manajemen keuangan serta desai kemasan dan pemantauan keberlanjutan kegiatan.

\section{HASIL DAN PEMBAHASAN}

Hasil pelaksanaan kegiatan Pengabdian kepada masyarakat diperlihatkan pada Tabel 1 . Mitra kerja yang ikut dalam kegiatan pelatihan pengemasan dan manajemen keuangan adalah 27 orang dengan distribusi pendidikan 10 orang SMU, 11 orang SMP dan 6 orang SD.

Rendahnya pengetahuan pengemasan dan pengelolaan keuangan di desa UD. Olivia Jaya 
Jurnal Teknologi Pangan Vol. 6 No. 2

Nopember 2015

Tabel 1. Target dan luaran program pengabdian

Target Luaran

1. Memberikan informasi peserta mengenai cara pengemasan yang baik pada keripik buahbuahan.

1. Pemahaman UKM, tentang pengemasan yang yang baik untuk penangana keripik buah-buahan.

2. Peserta dapat mengikuti pelatihan pengemasan keripik buah dengan baik dan pengelolaan keuangan dengan mengaplikasikan software keuangan.

2. Ketrampilan SDM dalam melakukan pengemasan keripik buah dengan baik dan pengelolaan keuangan melalui komputerisasi

3. Mempraktekkan cara mengemas keripik buahbuahan dengan baik dan benar serta mengelola keuangan melalui komputerisasi

4. Kemampuan berkreatifitas dan pola pikir dalam mengembangkan desain kemasan dan tata kelola keuangan.

3. Peserta pelatihan mampu melakukan pengemasan dengan baik dan benar serta mengelola keuangan melalui komputerisasi.

4. Peserta mengetahui cara mendesain kemasan dan mengelola keuangan secara komputerisasi.

dan Afalia Jaya merupakan fenomena yang menarik perhatian tim kerja untuk melatih dan mentransfer pengetahuan tengan pengemasan dan manajemen keuangan. Tabel 2 memperlihatkan jumlah mitra kerja yang pernah melakukan pengemasan dan manajemen keuangan dengan komputerisasi pada keripik buah-buahan sebelum kegiatan IbM dilaksanakan

Tabel 2. Mitra kerja yang pernah melakukan pengemasan sebelum kegiatan IbM

\begin{tabular}{llc}
\hline \multicolumn{2}{c}{ Keripik buah } & $\begin{array}{c}\text { Keripik } \\
\text { selain buah }\end{array}$ \\
\hline Pernah & 1 & 10 \\
Belum pernah & 26 & 17 \\
Jumlah & 27 & 27 \\
\hline
\end{tabular}

Mitra kerja yang berjumlah 27 orang belum pernah melakukan pengemasan pada keripik buah sebanyak 26 orang, sedangkan selain keripik buah sebanyak 17 orang (Tabel 2). Setelah melaksanakan kegiatan, ternyata 90\% mitra kerja dapat melakukan pengemasan dengan baik dan benar. Kondisi produk akan lebih menarik dan ketahanan produk meningkat dengan dilakukan pengolahan dan pengemasan yang benar. Peralatan pengemasan yang dimiliki mitra kerja menjadi modal penting dalam pengembangan produk dan peningkatan nilai jual keripik buahbuahan. Tabel 3 memperlihatkan sebanyak 26 orang belum pernah melakukan manajemen keuangan dengan komputerisasi pada usaha keripik buah-buahan, sedangkan selain keripik buah-buahan sebanyak 27 orang.

Tabel 3. Mitra kerja yang pernah melakukan manajemen keuangan dengan komputerisasi sebelum kegiatan IbM

\begin{tabular}{llc}
\hline \multicolumn{2}{c}{ Keripik buah } & $\begin{array}{c}\text { Keripik } \\
\text { selain buah }\end{array}$ \\
\hline Pernah & 1 & 0 \\
Belum pernah & 26 & 27 \\
Jumlah & 27 & 27 \\
\hline
\end{tabular}

Saat pelatihan kegiatan, tim pelaksana memberikan alternatif dan penjelasan yang mendasar serta sederhana. Penjelasan tersebut berkenaan dengan mitra kerja yang akan melaksanakan hasil dari pelatihan IbM tersebut.

\section{KESIMPULAN}

Dua tahapan kegiatan pengabdian kepada masyarakat yang telah dilakukan dapat disimpulkan bahwa:

1. Perlu kiranya dilakukan pelatihan yang lebih intensif untuk lebih banyak memberikan informasi terbaru mengenai pengemasan keripik buah yang baik dan benar.

2. Perlu adanya tindak lanjut dari kedua mitra untuk memaksimalkan kemampuan SDM dalam mengaplikasikan software manajemen keuangan 
Jurnal Teknologi Pangan Vol. 6 No. 2

Nopember 2015

\section{DAFTAR PUSTAKA}

Julianti, E. \& Nurminah, M. 2006. Teknologi Pengemasan. Medan: Departemen Teknologi Pertanian, Fakultas Pertanian, Universitas Sumatera Utara.

Natadjaja, L., Cahyono, Y.B. \& Yuwono, E.C. 2009. Kondisi desain kemasan produk makanan ringan dan minuman instant pada industri kecil skala rumah tangga (micro industry) di Kabupaten Kediri. Jurnal Desain Komunikasi Visual Nirmana 11 (2): 93-105.

Nurmedika, A., Marhawati, M., \& Alam, M. N. 2013. Analisis Pendapatan Dan Nilai Tambah Keripik Nangka Pada Industri Rumah Tangga Tiara Di Kota Palu.Agrotekbis 1 (3).

Octavia, M. 2010. Kajian manajemen teknologi pada kawasan sentra industri keripik Kota Bandar Lampung, Propinsi Lampung. Disertasi. IPB. Bogor.

Setiawan, J., Riyanto, B. \& Yuwono, E. C. 2013. Perancangan desain kemasan camilan tradisional marning jagung produksi soleh malang. Jurnal DKV Adiwarna 1(1).

Sulaawalia, 2009. Pentingnya melihat tanggal kadalwarsa pada label makanan dan minuman.

http://sulaawalia.blogdetik.com/2009/11/07/p entingnya-melihat-tanggal-kadalwarsa-padalabel-makanan-dan-minuman/. Diakses tanggal 17 april 2014

Sunoto, R. 2006. Pengaruh jenis kemasan terhadap kualitas dan umur simpan kripik nangka (Artocarpus heterophylla Lamk). Disertasi. Unika 
Jurnal Teknologi Pangan Vol. 6 No. 2

Nopember 2015 
Jurnal Teknologi Pangan Vol. 6 No. 2

Nopember 2015 
Jurnal Teknologi Pangan Vol. 6 No. 2

Nopember 2015 
Jurnal Teknologi Pangan Vol. 6 No. 2

Nopember 2015 